\title{
Surgical Outcome of Patients with Core-Biopsy-Proven Nonpalpable Breast Carcinoma: A Large Cohort Follow-Up Study
}

\author{
S. van Esser, MD ${ }^{1}$, N. H. G. M. Peters, MD, $\mathrm{PhD}^{2,3}$, M. A. A. J. van den Bosch, MD, $\mathrm{PhD}^{2}$, W. P. Th. M. Mali, MD, \\ $\mathrm{PhD}^{2}$, P. H. M. Peeters, MD, $\mathrm{PhD}^{3}$, I. H. M. Borel Rinkes, $\mathrm{MD}, \mathrm{PhD}^{1}$, and R. van Hillegersberg, MD, $\mathrm{PhD}^{1}$ \\ ${ }^{1}$ Department of Surgery, University Medical Center Utrecht, Utrecht, The Netherlands; ${ }^{2}$ Department of Radiology, \\ University Medical Center Utrecht, Utrecht, The Netherlands; ${ }^{3}$ Julius Center for Health Sciences and Primary Care, \\ University Medical Center Utrecht, Utrecht, The Netherlands; ${ }^{4}$ Department of Surgical Oncology, E01.805, University \\ Medical Center Utrecht, Utrecht, The Netherlands
}

\begin{abstract}
Background. Breast-conserving surgery (BCS) is the preferred treatment for nonpalpable breast carcinoma. The outcome, however, may be disappointing. In this study surgical outcome in a large cohort of patients diagnosed with nonpalpable breast carcinoma is evaluated.

Methods. In 833 patients with 841 nonpalpable breast carcinomas the number of re-excisions and type of surgical procedures was calculated and summed per patient. Subsequently, the number of conversions to mastectomy and the number of days until complete tumor removal were analyzed. In a subgroup analysis the patients with an in situ carcinoma were compared with the patients with an invasive carcinoma.

Results. The initial surgery consisted of BCS for 589 tumors $(70 \%)$ and of mastectomy for 242 tumors (29\%). For ten tumors $(1 \%)$ the initial surgery was unknown. After BCS, 158/589 tumors (27\%) required a re-excision: 116/ $337(34 \%)$ for the in situ carcinomas and 63/504 (13\%) for the invasive carcinomas $(p=0.0001)$. The number of conversions from BCS to mastectomy was 106/589 (18\%): $66 / 241(28 \%)$ in patients diagnosed with an in situ carcinoma versus $40 / 348(11 \%)$ in patients with an invasive carcinoma ( $p=0.0001)$. The median number of days until complete tumor removal was 28 , being 38 days for the in situ carcinomas and 25 days for the invasive carcinomas $(p=0.0001)$.
\end{abstract}

(C) The Author(s) 2009. This article is published with open access at Springerlink.com

First Received: 22 January 2009;

Published Online: 13 May 2009

S. van Esser, MD

e-mail: s.vanesser@umcutrecht.nl
Conclusions. There is room for improvement in the surgical treatment of nonpalpable breast carcinoma, especially the relatively favorable in situ carcinoma, as it requires significantly more excisions, mastectomies, conversions to mastectomy, and days for complete removal.

The most radical change in breast surgery has been the transition from modified radical mastectomy to breastconserving surgery (BCS), first described in $1969 .{ }^{1}$ Following several large randomized clinical trials that showed no difference in long-term survival after BCS compared with radical mastectomy, BCS in combination with radiotherapy became the new standard of care for women with early-stage breast carcinomas. ${ }^{2-4}$ Another example of the development towards a less-invasive approach of breast cancer diagnosis and treatment was the replacement of open breast biopsy by large core needle biopsy (LCNB). The Core Needle Biopsy after Radiological Localization (COBRA) study was conducted in 973 patients with radiologically suspicious nonpalpable breast lesions to assess whether the sensitivity and specificity of large core needle biopsy were comparable to the diagnostic performance of open breast biopsy. ${ }^{5}$ The results of this study showed a comparable diagnostic performance for large core needle biopsy and open breast biopsy. ${ }^{5,6}$ A second study (COBRA2000) was performed to assess the diagnostic performance of the COBRA guidelines outside a controlled study setting, i.e., in clinical practice. ${ }^{7}$ In clinical practice the sensitivity of LCNB of nonpalpable breast lesions approached the high sensitivity of the surgical excision biopsy. ${ }^{8}$

The introduction of large breast cancer screening programs in most Western countries resulted in the detection 
of larger numbers of early-stage invasive and in situ breast carcinomas. ${ }^{9}$ The increasing number of small, early-stage breast cancer stimulated the development of less-invasive diagnostic and treatment modalities. Early-stage, small nonpalpable tumors are difficult to discern at surgery. Therefore a guide wire is usually placed preoperatively to allow localization of the tumor. However, placement of the hooked guide wire may be difficult in patients with dense breast tissue. The likelihood of wire displacement is increased in these patients and repositioning of the wire in dense fibroglandular tissue is often problematic. Furthermore, surgical excision with tumor-free resection margins is technically challenging even with a perfectly placed wire. $^{10-12}$ The literature on surgical outcome purely focusing on nonpalpable breast cancer is scarce and often includes diagnostics excisions. ${ }^{13}$

Overall, in patients with a nonpalpable breast tumor, a re-excision is reported to be necessary in 40-56\%. ${ }^{14-17}$

The purpose of this study was to evaluate the number of re-excisions and the number of conversions from BCS to mastectomy in patients with a nonpalpable malignancy on LCNB. Furthermore, the time interval between LCNB diagnosis and complete removal of all tumorous tissue was assessed.

\section{MATERIALS AND METHODS}

\section{Patients}

Patients were retrieved from the COBRA/COBRA2000 study, which was conducted from 1997 to 2003.

This cohort was described in detail by Hoorntje et al. and Verkooijen et al. ${ }^{5,18}$ A total of 1,700 consecutive patients underwent LCNB. Inclusion criteria for this study included a nonpalpable malignancy (in situ or invasive) on LCNB and available histopathological data on both LCNB and surgical specimens. Exclusion criteria were missing pathology data until 1 year after biopsy and a benign LCNB diagnosis. Ultimately 856 patients diagnosed with an invasive or noninvasive carcinoma on LCNB were eligible for inclusion.

\section{Large Core Needle Biopsy}

LCNB was performed following a standard protocol in four medical centers. ${ }^{5}$ Lesions were localized with digital mammography. A minimum of five biopsy specimens was taken. In case of microcalcifications, at least eight specimens were obtained and specimen radiography was carried out to identify the calcifications in the biopsy specimen. After the LCNB, patients returned to the hospital that they were referred from. There, all further diagnostic (including histological analysis of the LCNB tissue samples) and therapeutic procedures were performed in a routine clinical setting. All patients with an in situ carcinoma or an invasive carcinoma underwent a hooked wire localized surgical excision.

\section{Histopathological Analysis}

Histopathological samples were taken from the macroscopically closest margin. Tumor free margins of $>1 \mathrm{~mm}$ were considered adequate. Tumor tissue in $\leq 2$ low-power fields (LPF) was considered focal irradicality and treated with local radiotherapy. Irradicality was defined as tumor tissue in $>2$ LPF and was treated with a re-excision or mastectomy.

\section{Data Collection and Analysis}

To avoid missing surgical procedures the number and type of surgical procedures, histopathological diagnosis, and time between the LCNB diagnosis and final surgery up to a maximum of 1 year after initial LCNB were extracted from the Dutch National Pathology Database (Pathologisch Anatomisch Landelijk Geautomatiseerd Archief, PALGA).

The first surgical procedure after LCNB was assessed, the number of initial planned mastectomies and the number of surgical procedures for complete tumor removal were calculated and summed per patient, and the number of conversions from BCS to mastectomy was documented. All LCNB (excluding the first one), lumpectomy, re-excisions, mastectomies, sentinel node biopsies, and axillary lymph node dissections were included in the analysis. Furthermore the total number of days between first LCNB and final removal of all tumorous tissue was calculated for each patient. To assess whether the number of surgical procedures differed between patients with in situ carcinoma and invasive carcinoma, a subgroup analysis was performed. Patients with pure invasive carcinoma were compared with patients with invasive and in situ carcinoma on final histopathology. Patients younger than the median age were compared with patients older than the median age. The number of surgical procedures and total number of days until all tumorous tissue was removed for both groups were compared using the $t$-test for the nonnormal distribution (Mann-Whitney $U$-test). The number of conversions to mastectomy for both groups was compared using the chi-square test. The number of surgical procedures after final histopathology was compared using the analysis of variance (ANOVA) and Bonferroni test. Differences in number of surgical interventions between younger or older than the median age were compared using the chi-square test. $p$-Value $<0.05$ was considered to be 
statistically significant. Data were analyzed using SPSS version 12.0.

\section{RESULTS}

After evaluation of the 856 eligible patients, 833 patients with 841 tumors were included in this study [mean age \pm standard deviation (SD) $60.0 \pm 9.9$ years]. In 4 patients no data on the initial core biopsy were available, in 7 patients core biopsy revealed no malignancy, and in 12 patients no data on follow-up after the core biopsy were available (Fig. 1). Pathology revealed 337 in situ carcinomas and 504 invasive carcinomas. The left breast was affected in 416 patients (49\%), the right breast in 408 patients (49\%), 8 patients had breast cancer in both breasts (1\%), and in 17 patients (2\%) the affected side was unknown (Table 1). The histological biopsy results are summarized in Table 1. The median histological tumor size was $12 \mathrm{~mm}$ (range $1-82 \mathrm{~mm}$ ).

The number of surgical procedures after LCNB ranged from one to four procedures, with a median of one. The initial surgery consisted of BCS for 589 tumors (70\%) and of mastectomy for 242 tumors (29\%). For ten tumors (1\%) the initial surgery was unknown. After BCS, 158/589 tumors $(27 \%)$ required a re-excision, consisting of $67 / 158$ tumors $(42 \%)$ of BCS and 91/158 tumors $(58 \%)$ of mastectomy. Twenty-one of these 158 tumors (13\%) required more than one re-excision (Fig. 2 and Table 2). Finally 106/589 (18\%) re-excisions after initial BCS were converted to a mastectomy. The median number of days from

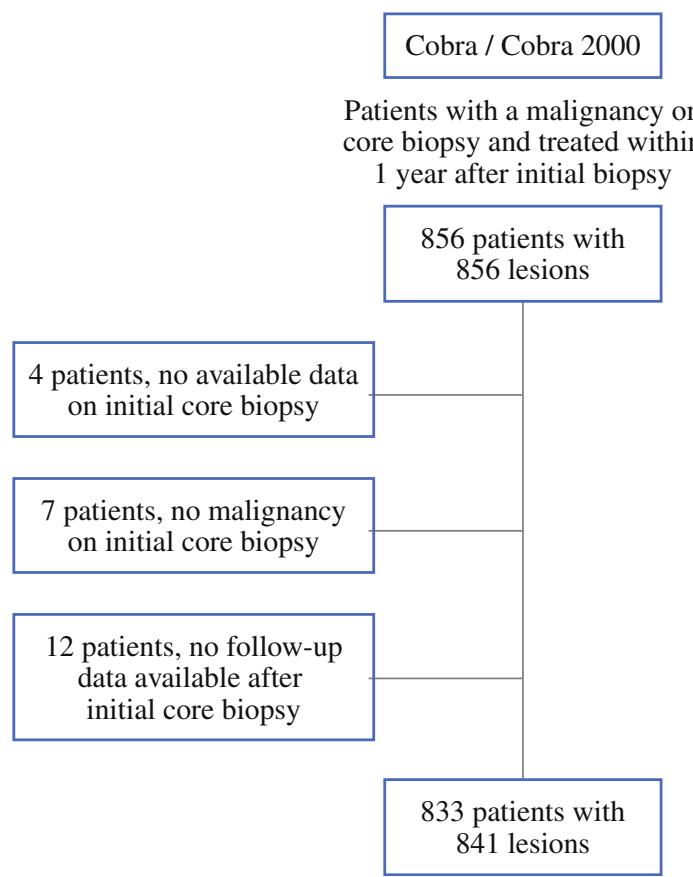

FIG. 1 Flowchart patient inclusion
TABLE 1 Baseline characteristics

\begin{tabular}{ll}
\hline Baseline characteristics & Frequency \\
\hline Number of patients & 833 \\
Number of tumors & 841 \\
Median age (years) & 60 \\
Affected side & \\
$\quad$ Left & 416 \\
Right & 408 \\
$\quad$ Unknown & 17 \\
Median tumor size (mm) & 12 \\
Median tumor size in situ on LCNB (range) & $12(1-80 \mathrm{~mm})$ \\
Median tumor size invasive on LCNB (range) & $12(2-82 \mathrm{~mm})$ \\
Histology (on LCNB) & \\
In situ & \\
DCIS & 307 \\
LCIS & 3 \\
Both & 2 \\
Invasive & \\
Ductal & 420 \\
Lobular & 69 \\
Both & 4 \\
Other breast malignancy & 29 \\
Unclear & 7 \\
\hline
\end{tabular}

the time of the LCNB until all tumorous tissue was removed was 28 .

Subgroup analysis showed that the median number of interventions after LCNB in both groups was one and the range was one to four interventions for the patients diagnosed with an in situ carcinoma and one to three for the patients diagnosed with an invasive carcinoma. Patients with an in situ carcinoma on LCNB initially underwent

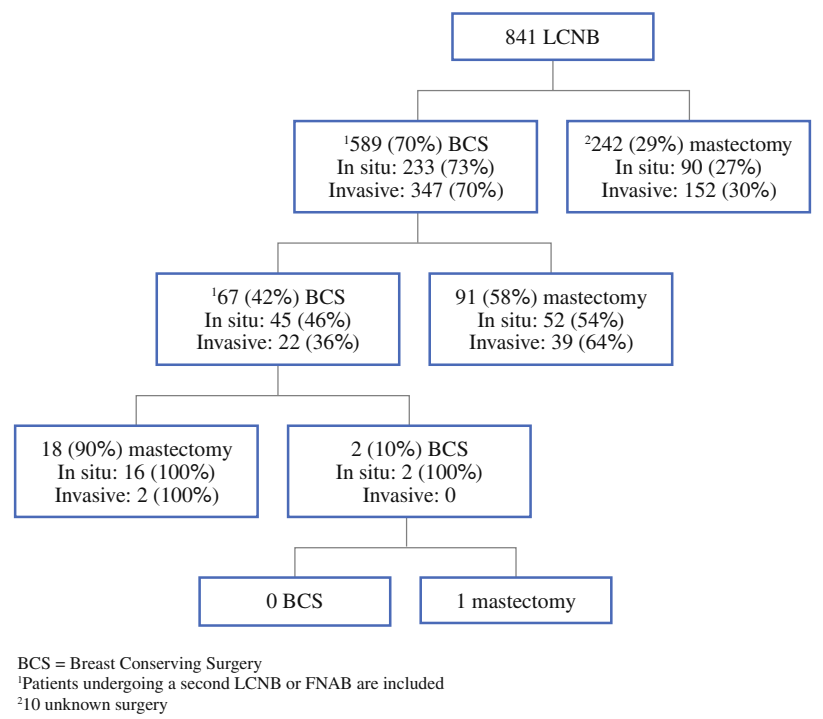

FIG. 2 Flowchart surgical procedures $(\mathrm{BCS}=$ breast conserving surgery) 
TABLE 2 Surgical procedures in both groups

\begin{tabular}{|c|c|c|c|}
\hline & $\begin{array}{l}\text { Invasive } \\
\text { carcinoma, } \\
n(\%)\end{array}$ & $\begin{array}{l}\text { In situ } \\
\text { carcinoma, } \\
n(\%)\end{array}$ & Total, $n(\%)$ \\
\hline \multicolumn{4}{|l|}{ First procedure } \\
\hline Breast conserving & $348^{\mathrm{a}}(70)$ & $241^{\mathrm{b}}(72)$ & $589(70)$ \\
\hline Mastectomy & $152(30)$ & $90(27)$ & $242(29)$ \\
\hline \multicolumn{4}{|l|}{ Second procedure } \\
\hline Breast conserving & $22(36)$ & $45(47)$ & $67(42)$ \\
\hline Mastectomy & $39(64)$ & $52(54)$ & $91(58)$ \\
\hline \multicolumn{4}{|l|}{ Third procedure } \\
\hline Breast conserving & 0 & $2(11)$ & $2(10)$ \\
\hline Mastectomy & 2 & $16(89)$ & $18(90)$ \\
\hline \multicolumn{4}{|l|}{ Fourth procedure } \\
\hline Breast conserving & 0 & 0 & 0 \\
\hline Mastectomy & 0 & 1 & $1(100)$ \\
\hline \multicolumn{4}{|l|}{ Total number of: } \\
\hline Breast conserving & $370(73)$ & $288(85)$ & $658(65)$ \\
\hline Mastectomy & $193(38)$ & $159(47)$ & $352(35)$ \\
\hline $\begin{array}{l}\text { Total number of conversions } \\
\text { from breast conserving } \\
\text { to mastectomy }\end{array}$ & $40^{\mathrm{c}}(11)$ & $66^{\mathrm{d}}(28)$ & $106(18)$ \\
\hline \multicolumn{4}{|l|}{${ }^{\mathrm{a}}$ Four missing } \\
\hline \multicolumn{4}{|l|}{ b Six missing } \\
\hline \multicolumn{4}{|l|}{${ }^{c}$ One missing } \\
\hline $\mathrm{d}$ Three missing & & & \\
\hline
\end{tabular}

significantly more breast amputations (Fig. 2 and Table 2) than patients with an invasive carcinoma: 157/337 (47\%) versus $193 / 504(38 \%)(p=0.01)$. The total number of reexcisions was 116/337 (34\%) for patients diagnosed with an in situ carcinoma and 63/504 (13\%) for patients diagnosed with an invasive carcinoma $(p=0.0001)$. The number of conversions from BCS to mastectomy differed significantly between both groups: 66/241 (28\%) in patients with an in situ carcinoma versus 40/348 (11\%) in patients with an invasive carcinoma $(p=0.0001)$. The difference in median number of days until all tumorous tissue was removed significantly differed as well: 25 days for patients with an invasive carcinoma and 38 days for patients with an in situ carcinoma $(p=0.0001)$.

Patients who showed invasive ductal carcinoma and ductal carcinoma in situ on histopathological evaluation after surgery had significantly more surgical interventions than patients with pure ductal carcinoma in situ $(p=0.048)$ and patients with pure invasive ductal carcinoma $(p=0.001)$. Next, patients who showed an invasive lobular carcinoma and an in situ lobular carcinoma on final histopathological evaluation had significantly more surgical interventions than patients with pure invasive lobular carcinoma $(p=0.01)$ and patients with an invasive ductal carcinoma $(p=0.03)$ (Table 3).

Patients who were younger than the median age (60 years) had significantly more surgical interventions than the patients older or equal to the median age $(p=0.021)$.

Finally in this study we found a 5-year survival of $93 \%$ for the patients with an invasive carcinoma and $98 \%$ for patients with an in situ carcinoma; the overall 5-year survival was $95 \%$.

\section{DISCUSSION}

To the best of our knowledge this is the first large study that solely describes the surgical performance of patients diagnosed with nonpalpable breast carcinoma. Our results show that a total of 179 tumors of the 841 (22\%) needed reexcisions to completely remove all tumorous tissue. The number of re-excisions was significantly higher in patients with an in situ carcinoma then in patients with an invasive carcinoma: $34 \%$ versus $13 \%(p=0.0001)$. The number of conversions from BCS to mastectomy was $18 \%$; this number was significantly higher in patients diagnosed with an in situ carcinoma: $28 \%$ versus $11 \%$ in patients with an invasive carcinoma $(p=0.0001)$. Patients with both an in

TABLE 3 Histopathological results after surgery

\begin{tabular}{llcc}
\hline Diagnosis & $\begin{array}{l}\text { Median histopathological } \\
\text { tumor size (range) }\end{array}$ & $\begin{array}{l}\text { Frequency (\%) } \\
\text { Mean number of } \\
\text { surgical interventions }\end{array}$ \\
\hline Pure DCIS & $20.00(2-80 \mathrm{~mm})$ & $206(24.5)$ & 2.29 \\
Pure invasive ductal carcinoma & $12.00(2-60 \mathrm{~mm})$ & $388(46.1)$ & 2.10 \\
Invasive ductal carcinoma and DCIS & $10.00(1-40 \mathrm{~mm})$ & $121(14.4)$ & 2.45 \\
Pure invasive lobular carcinoma & $15.00(3-82 \mathrm{~mm})$ & $50(5.9)$ & 2.14 \\
Invasive lobular carcinoma and LCIS & $6.00(5-8 \mathrm{~mm})$ & $3(0.4)$ & 3.00 \\
Invasive ductal carcinoma and invasive lobular carcinoma & $11.00(5-50 \mathrm{~mm})$ & $43(5.1)$ & 2.19 \\
LCIS and DCIS & $13.00(5-20 \mathrm{~mm})$ & $8(1)$ & 2.25 \\
Other & $12.00(3-50 \mathrm{~mm})$ & $22(2.6)$ & 2.00 \\
\hline
\end{tabular}


situ ductal carcinoma and an invasive ductal carcinoma on final histopathology and patients with both an in situ lobular carcinoma and an invasive lobular carcinoma had significantly more re-excisions than patients with pure invasive or in situ carcinomas. Patients younger than 60 years had significantly more re-excisions than patients aged 60 years or older.

Kurniawan et al. described the surgical outcome of patients with both palpable and nonpalpable breast carcinoma. All patients were included by way of the mammography screening program. The patients undergoing an initial mastectomy were excluded from this study. The percentage of initial mastectomies in this study was $9 \%$, which is lower than the percentage of initial mastectomies in our study. The number of irradical re-excisions in patients with both ductal carcinoma in situ (DCIS) and invasive ductal carcinoma was higher than in the patients with pure DCIS or pure invasive ductal carcinoma, corresponding with our findings.

Next, they describe $23 \%$ conversions from initial BCS to mastectomy. ${ }^{19}$ This percentage is higher than our overall percentage of conversions. This can be explained by the fact that all tumors were included in this study: palpable, nonpalpable, and T1-4 tumors, and the lower number of initial mastectomies. Our number of conversions to mastectomy is higher in patients diagnosed with an in situ carcinoma. Kurniawan et al. did not perform a subgroup analysis on the number of conversions for patients diagnosed with an in situ carcinoma.

There are several factors influencing the decision of performing a re-excision and the kind of surgery in (nonpalpable) breast cancer. Firstly, the definition of tumor-free margins is subject to discussion. The definition of tumorfree resection margins ranges from 1 to $5 \mathrm{~mm} .{ }^{13,20}$ In literature we found tumor-positive resection margins in 35$42 \%$ in patients with T1-4 tumors. ${ }^{13,21}$ Again the tumors described in these studies were both palpable and nonpalpable and larger (T1-4) than the tumors we analyzed. In these studies a tumor-free margin was defined as $>5 \mathrm{~mm}$ from the inked resection plain. The number of re-excisions we describe in this study is lower than described in the literature; possibly the fact that in our study a tumor-free margin of $>1 \mathrm{~mm}$ was considered adequate contributed to the lower number of re-excisions. Furthermore, in this study focal irradicality of the excised tumor was treated with radiotherapy as is described in literature. ${ }^{22}$

Secondly, the hooked wire placement is an important part of the surgical accuracy and is probably influenced by the experience of the radiologist. The hooked wire was placed in a routine clinical setting by both experienced and inexperienced radiologists. Wire-guided localization has several known disadvantages, such as wire displacement and the chance of a pneumothorax. ${ }^{11}$ Currently other localization techniques, including the promising radioguided occult lesion localization technique, are subjected to intensive research. ${ }^{23-26}$

Thirdly the experience of the surgeon performing the BCS is an important factor influencing the number of tumor-free margins. Dedicated breast surgeons obtain more tumor-free margins and perform less initial mastectomies than surgical residents or general surgeons. ${ }^{27,28}$ As in this study both general and dedicated breast surgeons performed the BCS and mastectomies, possibly the number of tumor-free margins was lower and the number of initial mastectomies was higher than when only dedicated breast surgeons participated. ${ }^{28}$ The overall number of days until all tumorous tissue was removed was 28 and differed significantly between in situ carcinomas and invasive carcinomas: 25 versus 38 days $(p=0.0001)$. In a study assessing differences in dedicated versus general surgeons the median duration from diagnosis to operation was found to be 5 weeks, which is similar to our data. ${ }^{28}$

Finally, the kind of treatment is influenced by the patient's desire. Although it is well known and overall accepted that the survival rates after breast-conserving procedures and breast amputations are the same in patients with small localized breast carcinomas, around $35 \%$ of the patients when offered the choice still choose to undergo a mastectomy. ${ }^{29,30}$ This could be an explanation for the high number of primary mastectomies.

Reliable preoperative imaging is important for excision with tumor-free margins of the tumor, especially in nonpalpable cancer that has to be radiologically localized prior to surgery. Mammography and ultrasound are the most widespread imaging modalities for imaging of breast tumors. Unfortunately these imaging modalities have limitations. Although not recorded in this study, overall mammography and ultrasound tend to underestimate the true tumor size as assessed on histopathology. The correlation improves in larger tumors. ${ }^{31}$ The patients with an in situ carcinoma scheduled for a BCS in this study underwent significantly more breast amputations than the patients with an invasive carcinoma. Limited possibilities to delineate the extent of in situ carcinoma with mammography and ultrasound could have contributed to the number of irradical excisions. Although current data on magnetic resonance imaging (MRI) are mixed, it could be more accurate in preoperative tumor size and distribution assessment and possibly reduce the number of reexcisions. $^{32-34}$

The difference in the number of days between patients with an in situ carcinoma and patients with an invasive carcinoma could also be explained by the fact that determining the extent of in situ carcinoma is difficult.

The survival found in this study is comparable to current literature. $^{35}$ 
In conclusion, in this study we showed that it is difficult to completely remove all tumorous tissue in one procedure. A total of $42 \%$ of patients diagnosed with early-stage nonpalpable breast cancer had a mastectomy. The treatment of in situ carcinoma is significantly more frequently converted from BCS to mastectomy than of invasive carcinoma. Improvements in preoperative imaging and surgical technique for nonpalpable breast carcinoma are needed to decrease the number of mastectomies.

ACKNOWLEDGMENT The authors would like to thank JWMAF Martens, MSc for his extensive help on the database.

OPEN ACCESS This article is distributed under the terms of the Creative Commons Attribution Noncommercial License which permits any noncommercial use, distribution, and reproduction in any medium, provided the original author(s) and source are credited.

\section{REFERENCES}

1. Mann BA, Samet JM, Hunt WC, Key CR, Goodwin JM, Goodwin JS. Changing treatment of breast cancer in New Mexico from 1969 through 1985. JAMA. 1988;259(23):3413-17.

2. Fisher B, Redmond C, Poisson R, et al. Eight-year results of a randomized clinical trial comparing total mastectomy and lumpectomy with or without irradiation in the treatment of breast cancer. N Engl J Med. 1989;320(13):822-8.

3. Fisher B. From Halsted to prevention and beyond: advances in the management of breast cancer during the twentieth century. Eur J Cancer. 1999;35(14):1963-73.

4. Veronesi U, Cascinelli N, Mariani L, et al. Twenty-year followup of a randomized study comparing breast-conserving surgery with radical mastectomy for early breast cancer. $N$ Engl $J$ Med. 2002;347(16):1227-32.

5. Verkooijen HM. Diagnostic accuracy of stereotactic large-core needle biopsy for nonpalpable breast disease: results of a multicenter prospective study with $95 \%$ surgical confirmation. Int $J$ Cancer. 2002;99(6):853-9.

6. Verkooijen HM, Borel RI, Peeters PH, et al. Impact of stereotactic large-core needle biopsy on diagnosis and surgical treatment of nonpalpable breast cancer. Eur J Surg Oncol. 2001; 27(3):244-9.

7. Hoorntje LE, Peeters PH, Mali WP, Borel RI. Is stereotactic largecore needle biopsy beneficial prior to surgical treatment in BIRADS 5 lesions? Breast Cancer Res Treat. 2004;86(2):165-70.

8. Peters N, Hoorntje L, Mali W, Borel RI, Peeters P. Diagnostic performance of stereotactic large core needle biopsy for nonpalpable breast lesions in routine clinical practice. Int $J$ Cancer. 2008;122(2):468-71.

9. Anttinen J, Kautiainen H, Kuopio T. Role of mammography screening as a predictor of survival in postmenopausal breast cancer patients. Br J Cancer. 2006;94(1):147-51.

10. De Cicco C, Pizzamiglio M, Trifiro G, et al. Radioguided occult lesion localisation (ROLL) and surgical biopsy in breast cancer. Technical aspects. Q J Nucl Med. 2002;46(2):145-51.

11. Nadeem R, Chagla LS, Harris O, et al. Occult breast lesions: a comparison between radioguided occult lesion localisation (ROLL) vs. wire-guided lumpectomy (WGL). Breast. 2005;14(4): 283-9.

12. Rahusen FD, Bremers AJ, Fabry HF, van Amerongen AH, Boom RP, Meijer S. Ultrasound-guided lumpectomy of nonpalpable breast cancer versus wire-guided resection: a randomized clinical trial. Ann Surg Oncol. 2002;9(10):994-8.

13. Florentine BD, Kirsch D, Carroll-Johnson RM, Senofsky G. Conservative excision of wire-bracketed breast carcinomas: a community hospital's experience. Breast J. 2004;10(5):398-404.

14. Besic N, Zgajnar J, Hocevar M, et al. Breast biopsy with wire localization: factors influencing complete excision of nonpalpable carcinoma. Eur Radiol. 2002;12(11):2684-9.

15. Thind CR, Desmond S, Harris O, Nadeem R, Chagla LS, Audisio RA. Radio-guided localization of clinically occult breast lesions (ROLL): a DGH experience. Clin Radiol. 2005;60(6):681-6.

16. Wallace AM, Daniel BL, Jeffrey SS, et al. Rates of reexcision for breast cancer after magnetic resonance imaging-guided bracket wire localization. J Am Coll Surg. 2005;200(4):527-37.

17. Zgajnar J, Hocevar M, Frkovic-Grazio S, Hertl K, Schweiger E, Besic N. Radioguided occult lesion localization (ROLL) of the nonpalpable breast lesions. Neoplasma. 2004;51(5):385-9.

18. Hoorntje LE, Peeters PH, Mali WP, Borel RI. Stereotactic large core needle biopsy for the diagnosis of nonpalpable breast lesions: reliable without additional excision biopsy. Ned Tijdschr Geneeskd. 2003;147(18):868-73

19. Kurniawan ED, Wong MH, Windle I, et al. Predictors of surgical margin status in breast-conserving surgery within a breast screening program. Ann Surg Oncol. 2008.

20. Singletary SE. Surgical margins in patients with early-stage breast cancer treated with breast conservation therapy. Am J Surg. 2002;184(5):383-93.

21. Karasawa K, Mitsumori M, Yamauchi C, et al. Treatment outcome of breast-conserving therapy in patients with positive or close resection margins: Japanese multi institute survey for radiation dose effect. Breast Cancer. 2005;12(2):91-8.

22. McIntosh A, Freedman G, Eisenberg D, Anderson P. Recurrence rates and analysis of close or positive margins in patients treated without re-excision before radiation for breast cancer. Am J Clin Oncol. 2007;30(2):146-51.

23. Van Esser S, Hobbelink M, Van der Ploeg IM, et al. Radio guided occult lesion localization (ROLL) for non-palpable invasive breast cancer. J Surg Oncol. 2008.

24. Layeequr RR, Iuanow E, Crawford S, Quinlan R. Sonographic hematoma-guided vs wire-localized lumpectomy for breast cancer: a comparison of margins and volume of resection. Arch Surg. 2007;142(4):343-6.

25. Medina-Franco H, Abarca-Perez L, Ulloa-Gomez JL, Romero C. Radioguided localization of clinically occult breast lesions (ROLL): a pilot study. Breast J. 2007;13(4):401-5.

26. Tafra L, Fine R, Whitworth $\mathrm{P}$, et al. Prospective randomized study comparing cryo-assisted and needle-wire localization of ultrasound-visible breast tumors. Am J Surg. 2006;192(4): 462-70.

27. Cleffken B, Postelmans J, Olde DS, Nap M, Schreutelkamp I, van der Bijl H. Breast-conserving therapy for palpable and nonpalpable breast cancer: can surgical residents do the job irrespective of experience? World J Surg. 2007;31(9):1731-6.

28. Zork NM, Komenaka IK, Pennington RE Jr, et al. The effect of dedicated breast surgeons on the short-term outcomes in breast cancer. Ann Surg. 2008;248(2):280-5.

29. Martin MA, Meyricke R, O'Neill T, Roberts S. Breast-conserving surgery versus mastectomy for survival from breast cancer: the Western Australian experience. Ann Surg Oncol. 2007;14(1): 157-64.

30. Collins ED, Moore CP, Clay KF, et al. Can women with earlystage breast cancer make an informed decision for mastectomy? $J$ Clin Oncol. 2009;27(4):519-25.

31. Golshan M, Fung BB, Wiley E, Wolfman J, Rademaker A, Morrow M. Prediction of breast cancer size by ultrasound, mammography and core biopsy. Breast. 2004;13(4):265-71. 
32. Braun M, Polcher M, Schrading S, et al. Influence of preoperative MRI on the surgical management of patients with operable breast cancer. Breast Cancer Res Treat. 2008;111(1):179-87.

33. Mann RM, Veltman J, Barentsz JO, Wobbes T, Blickman JG, Boetes $\mathrm{C}$. The value of MRI compared to mammography in the assessment of tumour extent in invasive lobular carcinoma of the breast. Eur J Surg Oncol. 2008;34(2):135-42.
34. Peters NH, van den Bosch MA, Peeters PH, Mali WM, Borel RI. Breast magnetic resonance imaging in early-stage breast cancer: is there really no value? J Clin Oncol. 2008;26(20):3465-6.

35. Kennedy T, Stewart AK, Bilimoria KY, Patel-Parekh L, Sener SF, Winchester DP. Treatment trends and factors associated with survival in T1aN0 and T1bN0 breast cancer patients. Ann Surg Oncol. 2007;14(10):2918-27. 